Article

\title{
Design of a New Compressed Air Energy Storage System with Constant Gas Pressure and Temperature for Application in Coal Mine Roadways
}

\author{
Kangyu Deng ${ }^{1}$, Kai Zhang ${ }^{1,2, * \mathbb{D}}$, Xinran Xue ${ }^{1,2}$ and Hui Zhou ${ }^{3}$ \\ 1 State Key Laboratory for Geomechanics \& Deep Underground Engineering, China University of Mining \& \\ Technology, Xuzhou 221116, Jiangsu, China; dky5646@cumt.edu.cn (K.D.); x.r.xue@cumt.edu.cn (X.X.) \\ 2 School of Mechanics \& Civil Engineering, China University of Mining \& Technology, Xuzhou 221116, \\ Jiangsu, China \\ 3 Institute of Rock and Soil Mechanics, Chinese Academy of Sciences, Wuhan 430071, Hubei, China; \\ hzhou@whrsm.ac.cn \\ * Correspondence: kzhang@cumt.edu.cn; Tel.: +86-185-014-10088
}

Received: 13 August 2019; Accepted: 31 October 2019; Published: 2 November 2019

check for updates

\begin{abstract}
Renewable energy (wind and solar power, etc.) are developing rapidly around the world. However, compared to traditional power (coal or hydro), renewable energy has the drawbacks of intermittence and instability. Energy storage is the key to solving the above problems. The present study focuses on the compressed air energy storage (CAES) system, which is one of the large-scale energy storage methods. As a lot of underground coal mines are going to be closed in China in the coming years, a novel CAES system is proposed for application in roadways of the closing coal mines. The new system combines pumped-hydro and compressed-air methods, and features constant air pressure and temperature. Another specific character of the system is the usage of flexible bags to store the compressed air, which can effectively reduce air leakage. The governing equations of the system are derived, and the response of the system is analyzed. According to the equations, for a roadway with depth of $500 \mathrm{~m}$ and volume of 10,000 cubic meters, the power generation capacity of the CAES system is approximately $18 \mathrm{MW}$ and the generating time is $1.76 \mathrm{~h}$. The results show that the new CAES system proposed is reasonable, and provides a suitable way to utilize the underground space of coal mines.
\end{abstract}

Keywords: compressed air energy storage (CAES) system; constant gas pressure; abandoned coal mine space; roadway; pumped-hydro storage (PHS)

\section{Introduction}

Renewable energy (wind and solar power, etc.) are developing rapidly in China and around the world. For example, the newly installed capacity of wind power in China in 2017 is 188.4 GW, which is $35 \%$ of the newly installed wind power in the world [1,2]. However, compared to traditional power (coal or hydro), renewable energy has the drawbacks of intermittence and instability. As a result, approximately $10 \%$ of the capacity of wind power is wasted in China.

Energy storage is the key to the above problems. There are many methods of energy storage, such as pumped-hydro storage (PHS), compressed air energy storage (CAES), flywheel energy storage, superconducting magnetic energy storage, and battery and super capacitor energy storage [3,4]. Among these methods, PHS and CAES are suitable for large-scale energy storage. Regarding the high efficiency of PHS, until the end of 2017, the capacity of PHS in China is $28.7 \mathrm{GW}$ and another $38 \mathrm{GW}$ worth of plants are under construction. However, the PHS plant has critical requirements of the geoconditions, 
especially in terms of the altitude difference. Therefore, the sites of PHS plants may not be consistent with those of renewable energy $[5,6]$.

As for CAES, there are several technical solutions, such as liquid air energy storage [7], underwater constant air pressure energy storage [8], Isothermal CAES [9], supercritical CAES [10], and advanced adiabatic CAES [11]. There are now two operating large-scale CAES plants, which are in America and Germany $[12,13]$. Both plants use salt caverns to store the compressed air. In China, some companies are also planning to construct CAES plants using salt caverns [14]. However, the geographical distribution of suitable rock salt is a problem for these projects. Alternatively, using caverns in hard rock for CAES may become an effective method in China. The reason is that a lot of coal mines are now closed to optimize coal production capacity in China. For example, over 500 coal mines were closed in 2018. There are many roadways in the closed coal mines, which are suitable for storing compressed air after some modification $[15,16]$.

Researchers have studied CAES in caverns of hard rock, and have proposed some possible scenarios. At present, the main problem with CAES in hard rock caverns is the tightness and the stability of the surrounding rock [17-19]. The underground cavern of the CAES station is large-scale $\left(10^{5}-10^{6} \mathrm{~m}^{3}\right)$, has high air pressure (5-10 MPa or more), and strict sealing requirements (leakage rate in $24 \mathrm{~h}$ should not be more than $0.5 \%-1.0 \%$ ) [20-24]. Thus, the inner wall of the gas storage cavern generally needs to be lined and sealed, as shown in Figure 1.

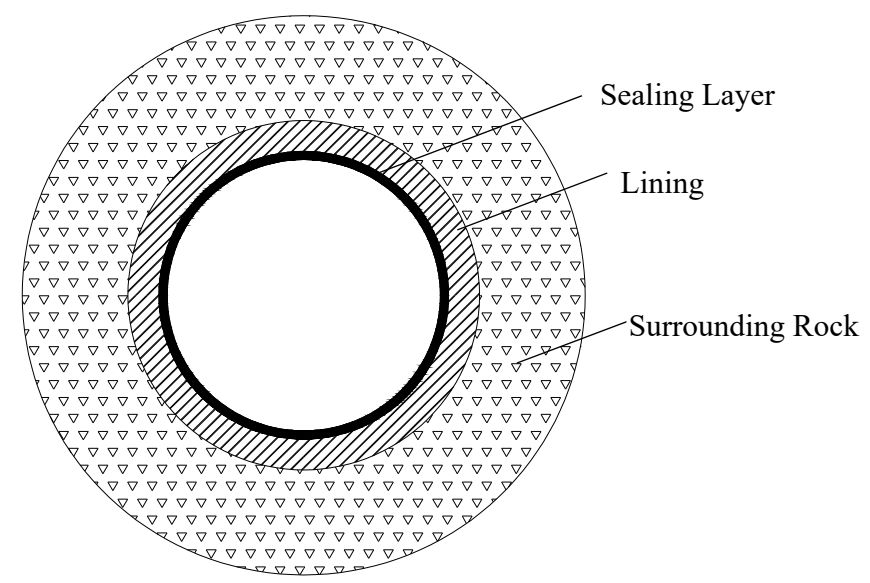

Figure 1. The structure of a compressed air energy storage (CAES) cavern.

The distribution and geological conditions of roadways in coal mines is different from other caverns. Some particular spaces in coal mines, such as vertical shafts, can also be used. Therefore, the current scenarios mentioned above for hard rock caverns may not be the best choice for coal mines. In the current research, a new CAES scheme is proposed for coal mine roadways. The new scheme has two special features. Firstly, PHS and CAES are combined, and the pressure of the compressed air is kept constant by pumping water through the vertical shaft. Secondly, the compressed air is stored in flexible bags, and the leakage of air can be well controlled. The control equations of the CAES system are proposed, and the key parameters are analyzed.

\section{Design of a New Compressed Air Energy Storage System in Hard Rock}

\subsection{Methodology of the Research}

The configuration of a CAES system is complicated. The present research focuses on the possible application of the system in underground coal mines. Some specific characteristics of the CAES system are investigated. The methodology of the research is as follows:

(1) Investigate the conditions of different roadways in underground coal mines. 
(2) Describe the typical configuration of a CAES system and propose a new CAES system for application in coal mine roadways, which features a combination of pumped-hydro and compressed-air methods, and utilization of flexible bags to store compressed air.

(3) Deduce the governing equations of the new CAES system to investigate the response of the system during release of compressed air.

(4) Carry out case studies to investigate the power generator capacity and operation time with roadways of different depths.

(5) Summarize the advantages of the proposed CAES system.

\subsection{Distribution of Roadways in Underground Coal Mines}

The coal mines mentioned here are for underground mining. In these coal mines, at least two vertical or inclined shafts are first excavated for ventilation and transport. There are three types of underground roadways: (1) development roadways, which serve the entire mine or a mining level, and are mainly distributed in hard rocks (such as sandstone); (2) preparation roadways, which serve a specific mining area, and the surrounding rock is mainly rock mass; (3) mining roadways, which serve one or two mining faces and are located in coal seams $[25,26]$. Among these roadways, the support strength of development roadways is the highest. After the mining progress, the mining roadways collapse and the preparation roadways may undergo large deformation. Therefore, only the development roadways are suitable for implementing a CAES system.

The section area of development roadways is generally over $10 \mathrm{~m}^{2}$, and the length may be several kilometers. Therefore, the possible volume for storing compressed air can be several tens or hundreds of thousands of cubic meters, which is sufficient for a large-scale CAES plant.

\subsection{Brief Introduction of a Compressed Air Energy Storage System}

A typical CAES system without heat storage has three parts, as seen in Figure 2a, i.e., air compressing (electromotor and compressor), air storage, and the power-generating unit (turbine and generator). In the air compressing unit, the air is compressed to a specific pressure [27-29]. If the required air pressure is high (for example, $10 \mathrm{MPa}$ ), a multistage compression procedure should be used to increase the efficiency. During the compressing process, the air temperature increases, which makes it difficult to compress the air further. Therefore, the air should be cooled during compression.

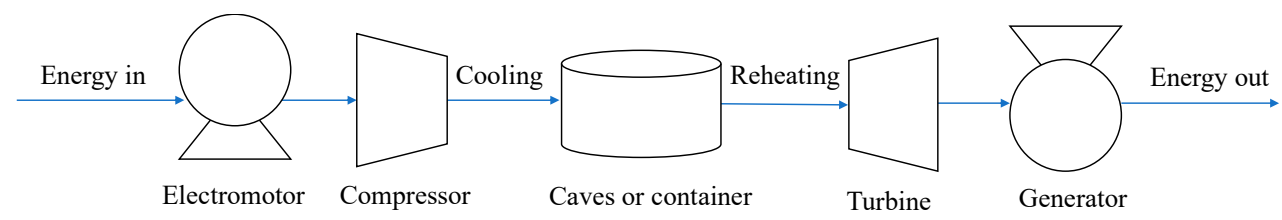

(a)

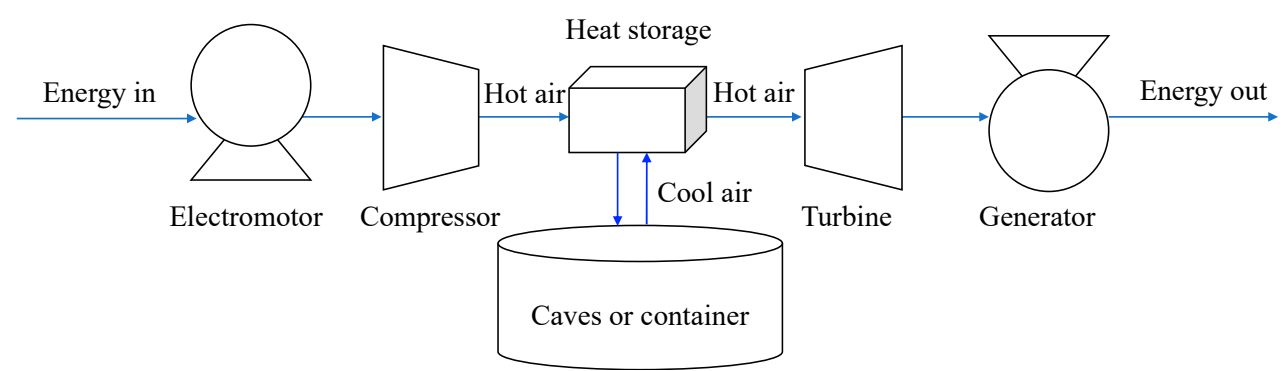

(b)

Figure 2. Structure of a CAES system: (a) without heat storage; and (b) with heat storage.

The air storage unit is usually the most costly part in the CAES system, and it can utilize caverns in rock mass, steel containers, flexible bags, etc. [30]. 
The power-generating unit is composed of multistage turbines and a generator, and extracts energy by expanding the compressed air. The compressed air flows through the turbines and changes into cold air with low pressure. To increase the efficiency of the system and prevent the temperature of the export air from being too low, the compressed air should be heated by burning natural gas or electric heating [31].

As the air should be cooled during compressing and heated before flowing into the turbines, a lot of energy is wasted, and the efficiency of the CAES system is low (approximately $42 \%$ for the plant in Germany). Thus, an advanced CAES system, as seen in Figure $2 b$, has been proposed with heat storage [32]. In the advanced system, the heat during compression is stored in a heat-exchanging unit, and the final compressed air is at approximately room temperature. When generating electricity, the compressed air first flows into the heat-exchanging unit and is heated to high temperature, then expands in the turbines. The advanced scheme has a much higher efficiency (over 60\%).

\subsection{Design of a New Compressed Air Energy Storage System for Application in Coal Mine Roadways}

For an efficient CAES system, several principles should be followed. (1) The air pressure should be kept as constant as possible, as this will cause the turbines to work efficiently around the rated state. (2) The thermal energy of the compressed air should be properly treated. When the air is compressed, it will emit heat. If the heat is not stored, the efficiency of the system will inevitably decrease. (3) Leakage of compressed air should be controlled.

Based on the current technology of CAES and the conditions of roadways in coal mines, a new CAES system is proposed here. According to the principles mentioned above, the remarkable solutions in the new system are as following:

(1) The pump-hydro and compressed air methods are combined. This makes the air pressure constant during the electricity generation. First, a reservoir is constructed in the ground. Then, during the electricity generating operation of the CAES system, the water in the reservoir flows into the roadway through the pipes in the vertical shaft and pressurizes the air. As the variation of water pressure is small, the air pressure can be maintained. Finally, during the air charging period, the water in the roadway is pumped into the reservoir.

(2) Flexible bags are used to store compressed air in the roadways. The bags may be produced using rubber or other cheap materials. There are two reasons for this scheme: the first is to separate the air from the water; the other is to prevent the air from leaking into the surrounding rock, as the flexible bags have much lower permeability than concrete or rock.

(3) Heat storage is applied. During the compression process, the heat will be stored and the compressed air temperature will be reduced to that of surrounding rock of the roadway. By doing this, the heat exchange between the stored air and the surrounding rock can be substantially reduced, and thermal energy loss is controlled. During the electricity generation process, the air will be heated using the stored thermal energy before flow into the turbines.

The layout of the new CAES system is shown in Figure 3. Firstly, the maximum pressure of the compressed air is calculated based on the pressure head of the reservoir. Secondly, the surrounding rock of the roadway is reinforced according to the air pressure. In practice, the surrounding rock can be treated with grouting to strengthen the damage zones, and then supported using a concrete lining. Thirdly, the flexible bags are designed to have the same cross section shape as the roadway, but with slightly larger size. When the compressed air is stored in the bags, there will be no tensile stress distributed in the bag wall, which makes it quite simple to maintain the integrity of the bags. Fourthly, the parameters of the turbines are designed to make the system work around the rated state based on the thermodynamic state of the compressed air at the outlet. 


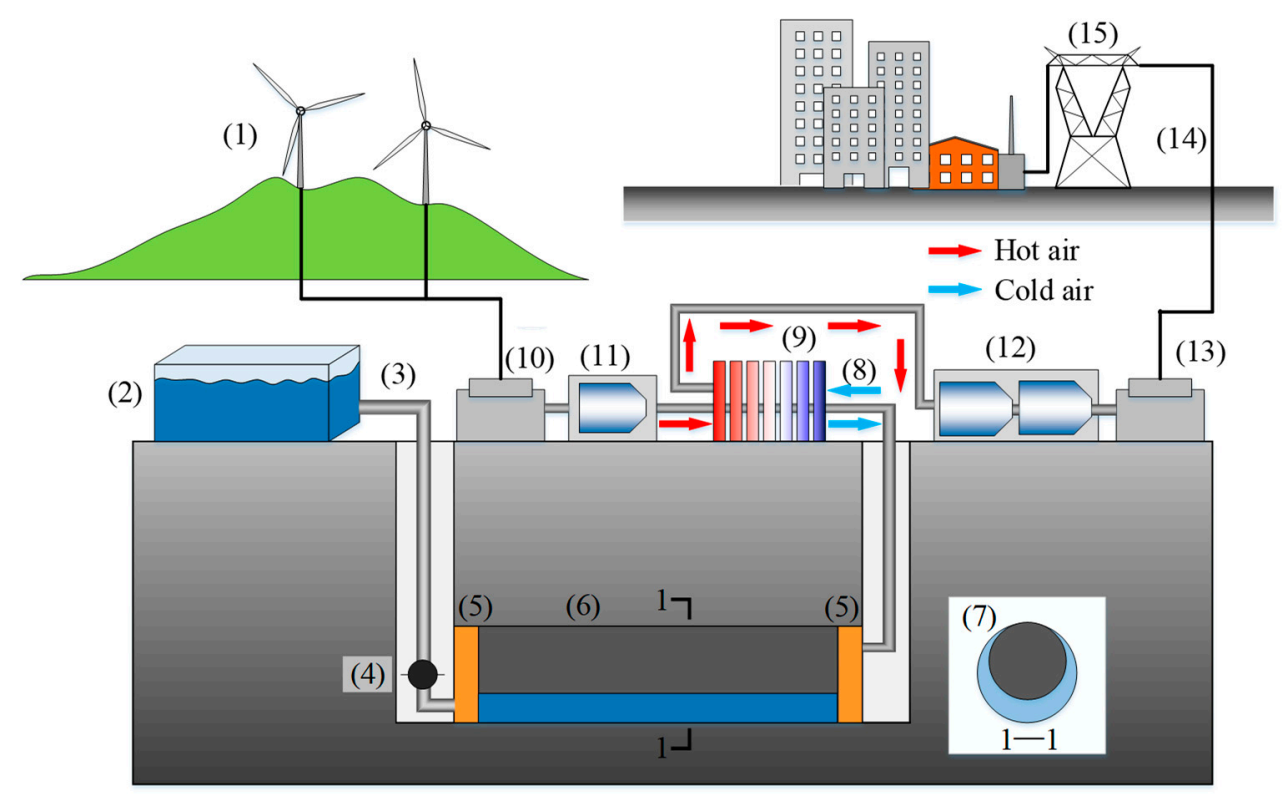

Figure 3. Layout of the new CAES system: (1) renewable energy; (2) reservoir; (3) water pipe; (4) water pump; (5) plugging wall; (6) roadway; (7) flexible bags; (8) compressed air pipe; (9) heat storage unit; (10) electromotor; (11) compressor; (12) turbines; (13) generator; (14) power lines; and (15) power grid.

\section{Analysis of the New Compressed Air Energy Storage System}

\subsection{Fundamental Assumptions}

For the new CAES system, some assumptions are made to simplify the analysis, which are:

(1) The compressed air has been cooled to the temperature of the roadway before being stored in the flexible bags. Therefore, there will be no thermal exchange between the compressed air and the environment during the storage period.

(2) The thermal exchange between the compressed air and the water during air release is neglected. Thus, the temperature of the compressed air in the flexible bags is constant.

(3) The reservoir is large enough, and the variation of the pressure head during air release is neglected. Therefore, the pressure head at the bottom of the water pipe is constant.

(4) The pressure loss of water in the roadway is neglected, as the flow is slow.

(5) During air release, the distribution of air pressure in the flexible bags is uniform. That is to say, the transmission of air pressure between the two plugging walls is assumed to be instantaneous. In reality, the air pressure at the plugging wall around the compressed air pipe is lower than that around the water pipe.

\subsection{Equations of the New Compressed Air Energy Storage System}

In the present study, only the response of the air storage part of the system is analyzed, and the equations of the compressor, turbines, and heat storage unit are not included. For the air storage part, two kinds of variables are involved, i.e., water-related and compressed air-related variables, which are denoted by a subscript " $w$ " or " $a$ ", respectively, in the following.

Based on the assumptions listed above, the variables of the system can be reduced. The main variables are shown in Figure 4. During the storing air period, the compressed air is pumped into the flexible bags until the air pressure reaches a specific value. In this period, the water does not flow and the considered variable of the system is only the air pressure in the bag. However, in the process of releasing air, the air and water will move simultaneously, and the response of the system is more complicated. Therefore, here, we only analyze the process of releasing air. 


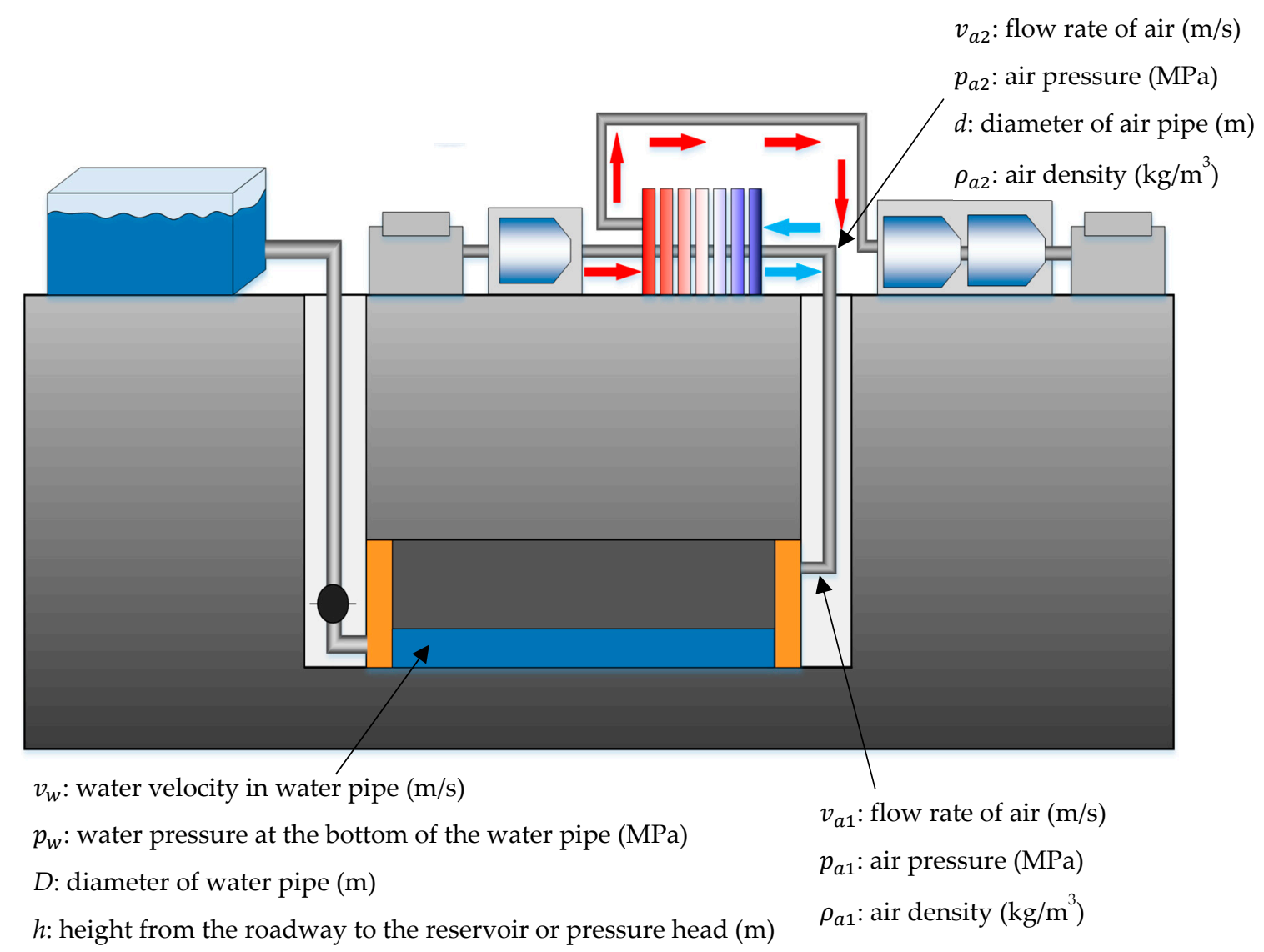

Figure 4. Variables of the storage part of the CAES system.

According to the configure of the turbines, a constant mass flow rate is set to operate at the rated power, which is represented by $\dot{m}_{a}$. Then, based on the mass conservation of the compressed air at the inlet and outlet of air pipe, we get:

$$
\left\{\begin{array}{l}
\dot{m}_{a}=v_{\mathrm{a} 1} \rho_{\mathrm{a} 1} \pi \frac{d^{2}}{4} \\
\dot{m}_{a}=v_{\mathrm{a} 2} \rho_{\mathrm{a} 2} \pi \frac{d^{2}}{4}
\end{array}\right.
$$

where $v_{\mathrm{a} 1}$ and $\rho_{\mathrm{a} 1}$ are the velocity and density of the compressed air at the inlet of the air pipe, respectively. $v_{\mathrm{a} 2}$ and $\rho_{\mathrm{a} 2}$ are the velocity and density of the compressed air at the outlet of the air pipe, respectively. $d$ is the diameter of the air pipe.

The density $\rho_{\mathrm{a} 1}$ and $\rho_{\mathrm{a} 2}$ relate to the air pressure according to the gas state equation, which are:

$$
\left\{\begin{array}{l}
\rho_{\mathrm{a} 1}=\frac{p_{\mathrm{a} 1}}{Z R T} \\
\rho_{\mathrm{a} 2}=\frac{p_{\mathrm{a} 2}}{Z R T}
\end{array}\right.
$$

where $p_{\mathrm{a} 1}$ is the pressure of compressed air at the inlet of air pipe. $p_{\mathrm{a} 2}$ is the pressure of compressed air at the outlet of air pipe. $Z$ is the compressibility factor, which depends on temperature and pressure, and is 1 for an ideal gas. $R$ is the gas constant, which is $287 \mathrm{~J} /(\mathrm{kg} \cdot \mathrm{K}) . T$ is the air temperature in Kelvin.

When the flexible bag is discharged under constant pressure, due to the influence of friction and gravity, the air will undergo a pressure drop in the air pipe. The relation between the air pressure at the inlet and outlet of the air pipe is [33,34]:

$$
p_{\mathrm{a} 1}^{2}-p_{\mathrm{a} 2}^{2} e^{b h}=c \dot{m}_{\mathrm{a}}{ }^{2 e^{b h}-1}
$$


where $b$ is a parameter and equals to $\frac{2 g}{R T}$, and $g$ is the acceleration of gravity. $c$ is a parameter and equal to $\lambda \frac{16 Z R T}{\pi^{2} d^{5}}$, where $\lambda$ is the friction coefficient along the pipe. $h$ is the height from the roadway to the reservoir.

For the water, according to the Bernoulli equation, the relation between the pressure head at the lower end of water pipe and reservoir is as follows:

$$
h=\frac{p_{\mathrm{w}}}{\rho_{\mathrm{w}} g}+\frac{v_{\mathrm{w}}^{2}}{2 g}+h_{\mathrm{f}}+h_{\mathrm{j}}
$$

where $p_{\mathrm{w}}$ is the water pressure at the bottom of the water pipe, and is equal to $p_{\mathrm{a} 1}$ according to the assumption in Section 3.1. $\rho_{\mathrm{w}}$ is the density of water, which is $1000 \mathrm{~kg} / \mathrm{m}^{3} . v_{\mathrm{w}}$ is the water velocity in the pipe. $h_{\mathrm{f}}$ is the major head loss along the water pipe, and $h_{\mathrm{j}}$ is the minor head loss at the junction of water pipe and roadway, which can be determined by:

$$
\left\{\begin{array}{c}
h_{\mathrm{f}}=\lambda \frac{h}{D} \frac{v_{\mathrm{w}}{ }^{2}}{2 g} \\
h_{\mathrm{j}}=\xi \frac{v_{\mathrm{w}}^{2}}{2 g}
\end{array}\right.
$$

where $\xi$ is the local friction coefficient, which is 1 here for the water flowing from pipe to roadway. $D$ is the diameter of the water pipe.

As the volume flow rate of water equals to that of compressed air at the inlet of the air pipe, $v_{\mathrm{w}}$ has a relation with $v_{\mathrm{a} 1}$ as:

$$
v_{\mathrm{w}}=\frac{d^{2}}{D^{2}} v_{\mathrm{a} 1}
$$

Combining Equations (1)-(6), we get the governing equations of the new CAES system as follows:

$$
\left\{\begin{array}{c}
\dot{m}_{a}=v_{\mathrm{a} 1} \frac{p_{\mathrm{a} 1}}{\mathrm{ZRT}} \pi \frac{d^{2}}{4} \\
\dot{m}_{a}=v_{\mathrm{a} 2} \frac{p_{\mathrm{a}}}{\mathrm{ZRT}} \pi \frac{d^{2}}{4} \\
p_{\mathrm{a} 1}^{2}-p_{\mathrm{a} 2}^{2} e^{b h}=c \dot{m}_{\mathrm{a}} e^{\frac{e^{b h}-1}{b}} \\
h=\frac{p_{\mathrm{w}}}{\rho_{w w} g}+\frac{v_{\mathrm{w}}{ }^{2}}{2 g}+\lambda \frac{h}{D} \frac{v_{\mathrm{w}}{ }^{2}}{2 g}+\xi \frac{v_{\mathrm{w}}}{2 g} \\
v_{\mathrm{W}}=\frac{d^{2}}{D^{2}} v_{a 1} \\
p_{\mathrm{w}}=p_{\mathrm{a} 1}
\end{array}\right.
$$

In Equation (7), there are six variables that need to be solved, i.e., $p_{\mathrm{a} 1}, p_{\mathrm{a} 2}, v_{\mathrm{a} 1}, v_{\mathrm{a} 2}, v_{\mathrm{w}}, p_{\mathrm{w}}$. The equations can be solved, given the air mass flow rate, $\dot{m}_{\mathrm{a}}$ and the pressure head of the reservoir, $h$.

The power of the electric generator is a key factor for determining the scale of the CAES plant. The main factors affecting generator power include air pressure and temperature, air mass flow rate, turbine efficiency, and generator efficiency. For the CAES system, the output power of the electric generator is [35,36]:

$$
P_{g}=\frac{k}{k-1} R T_{\mathrm{a} 3}\left[1-\left(\frac{p_{\mathrm{atm}}}{p_{\mathrm{a} 2}}\right)^{\frac{k-1}{k}}\right] \dot{m}_{\mathrm{a}} \eta_{\mathrm{t}} \eta_{\mathrm{g}}
$$

where $P_{\mathrm{g}}$ is the output power of the electric generator. $T_{\mathrm{a} 3}$ is the air temperature at the inlet of the turbines. $P_{\mathrm{atm}}$ is atmospheric pressure. $\eta_{\mathrm{t}}$ and $\eta_{\mathrm{g}}$ are the efficiency of turbines and electric generator, respectively, which are approximately 0.8 to 0.9 .

\subsection{Response of the System during Air-Releasing Operation}

At present, the depth of coal mines in China is generally between $300 \mathrm{~m}$ and $1000 \mathrm{~m}$. Two possible CAES systems at the depth of $500 \mathrm{~m}$ and $1000 \mathrm{~m}$ are analyzed here, and the volume of the roadway is assumed to be $10,000 \mathrm{~m}^{3}$. The values of the system parameters are listed in Table 1 . 
Table 1. Values of the system parameters.

\begin{tabular}{cc}
\hline Item & Value \\
\hline Temperature of the roadway $(T)$ & $283.15 \mathrm{~K}$ \\
Atmospheric pressure $\left(P_{\mathrm{atm}}\right)$ & $0.10 \mathrm{MPa}$ \\
Section area of roadway & $10 \mathrm{~m}^{2}$ \\
Length of roadway & $1000 \mathrm{~m}$ \\
Diameter of water pipe & $1 \mathrm{~m}$ \\
Diameter of air pipe & $0.5 \mathrm{~m}$ \\
Friction coefficient along the air pipe and water pipe $(\lambda)$ & 0.02 \\
local friction coefficient $(\xi)$ & 1 \\
Air temperature at the inlet of turbines $\left(T_{\mathrm{a} 3}\right)$ & $383.15 \mathrm{~K}$ \\
Gas constant $(R)$ & $287 \mathrm{~J} /(\mathrm{kg} \cdot \mathrm{K})$ \\
Expander efficiency $\left(\eta_{\mathrm{t}}\right)$ & 0.84 \\
Power generator efficiency $\left(\eta_{\mathrm{g}}\right)$ & 0.84 \\
Adiabatic exponent $(k)$ & 1.4 \\
\hline
\end{tabular}

\subsubsection{Compressed Air Energy Storage System at Depth $h=500 \mathrm{~m}$ and $\dot{m}_{\mathrm{a}}=100 \mathrm{~kg} / \mathrm{s}$}

Taking a medium-scale turbine as an example, we assume that mass flow rate $\dot{m}_{\mathrm{a}}$ is $100 \mathrm{~kg} / \mathrm{s}$. Equation (7) is solved according to the parameters in Table 1, and the results are listed in Table 2. It can be seen that the pressure loss in the water pipe is approximately $0.13 \mathrm{MPa}$, while that in the air pipe is $0.33 \mathrm{MPa}$. The pressure loss depends on the parameters of the pipes, i.e., the diameters and friction coefficient. The relations between the air pressure at the inlet $\left(p_{\mathrm{a} 1}\right)$ and outlet $\left(p_{\mathrm{a} 2}\right)$ and the pipeline parameters are analyzed and shown in Figure 5a,b. The results show that smaller cross sections of the water and air pipes will induce larger pressure loss of the final air pressure $\left(p_{\mathrm{a} 2}\right)$, especially when the diameter of water pipe $(D)$ is less than $0.8 \mathrm{~m}$ and that of air pipe $(d)$ is less than $0.5 \mathrm{~m}$ for the roadway with $500 \mathrm{~m}$ depth. From Figure $5 \mathrm{c}$, it can be seen that the friction coefficient has a clear effect on the final air pressure, i.e., the higher the friction coefficient, the lower the final air pressure. Therefore, according to the acquirement of the CAES system and the economic factors, the optimal diameters for water and air pipes are $0.8 \mathrm{~m}$ and $0.5 \mathrm{~m}$, respectively, and the friction coefficient of the pipes should be decreased as much as possible.

Table 2. Results for a CAES system in a roadway with different depths.

\begin{tabular}{ccc}
\hline \multirow{2}{*}{ Parameter } & \multicolumn{2}{c}{ Values } \\
\cline { 2 - 3 } & $\mathbf{5 0 0} \mathbf{~ m ~ D e p t h}$ & $\mathbf{1 0 0 0} \mathbf{~ m ~ D e p t h}$ \\
\hline$p_{\mathrm{a} 1}$ & $4.87 \mathrm{MPa}$ & $9.79 \mathrm{MPa}$ \\
$p_{\mathrm{w}}$ & $4.87 \mathrm{MPa}$ & $9.79 \mathrm{MPa}$ \\
$p_{\mathrm{a} 2}$ & $4.54 \mathrm{MPa}$ & $8.60 \mathrm{MPa}$ \\
$v_{\mathrm{w}}$ & $2.06 \mathrm{~m} / \mathrm{s}$ & $1.03 \mathrm{~m} / \mathrm{s}$ \\
$v_{\mathrm{a} 1}$ & $8.24 \mathrm{~m} / \mathrm{s}$ & $4.10 \mathrm{~m} / \mathrm{s}$ \\
$v_{\mathrm{a} 2}$ & $8.85 \mathrm{~m} / \mathrm{s}$ & $4.67 \mathrm{~m} / \mathrm{s}$ \\
$P_{\mathrm{g}}$ & $18.0 \mathrm{MW}$ & $19.52 \mathrm{MW}$ \\
\hline
\end{tabular}

According to the parameters in Table 1, the power generation capacity of the system is calculated by using Equation (8) and listed in Table 2. For the given air mass flow rate, the power generation capacity of the CAES system is approximately $18.0 \mathrm{MW}$, which is equivalent to the capacity of eight general wind turbine generator sets. For the $10,000 \mathrm{~m}^{3}$ space volume, the power generation duration of the CAES system can be calculated according to Equation (9), which is approximately $1.76 \mathrm{~h}$, which is practical for power grid peak shaving.

$$
t=\frac{\rho_{\text {storage }} V_{\text {storage }}}{\dot{m}_{\mathrm{a}}}
$$


where $\rho_{\text {storage }}$ is the air density in the flexible bags. $V_{\text {storage }}$ is the volume of the roadway.

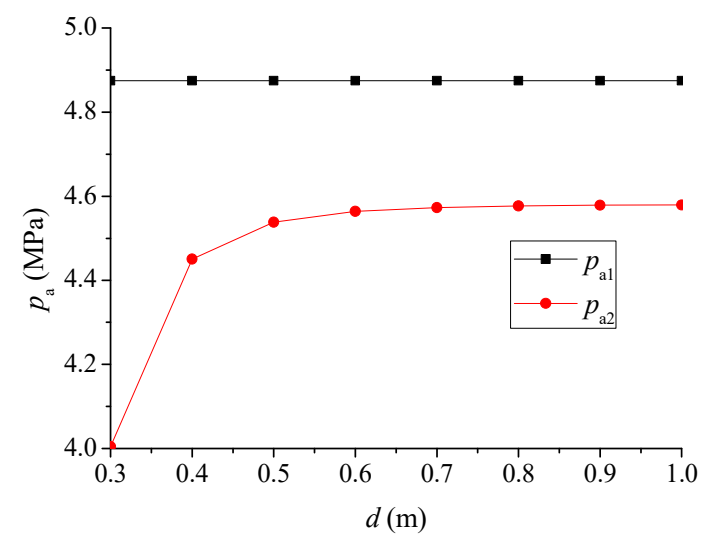

(a)

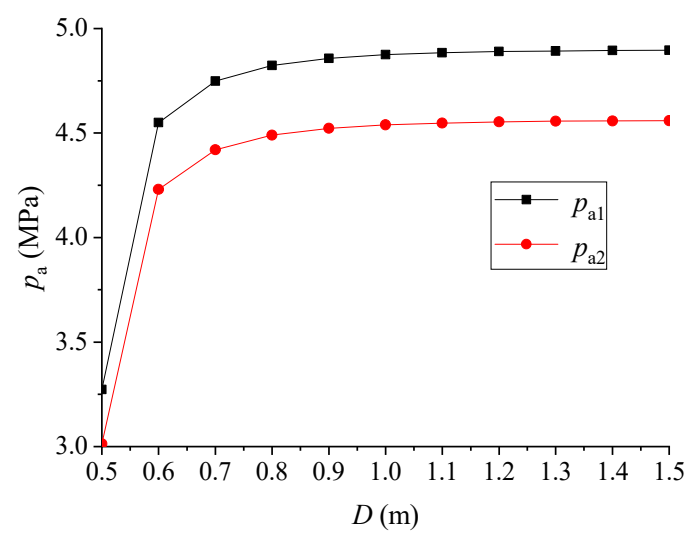

(b)

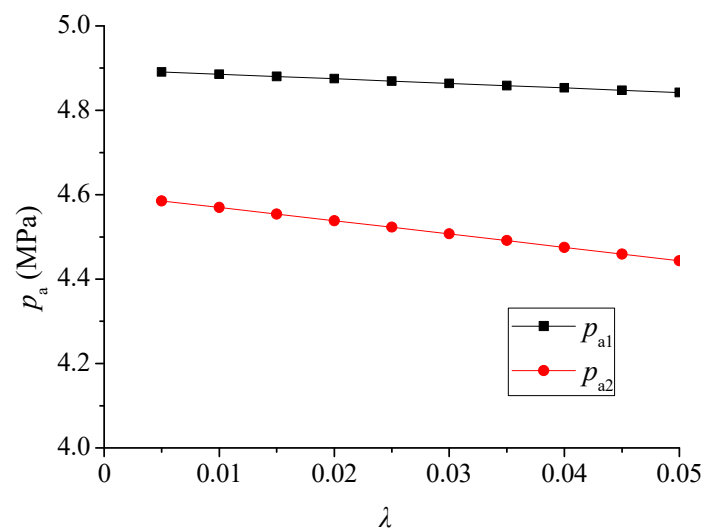

(c)

Figure 5. Variation of $p_{\mathrm{a} 1}$ and $p_{\mathrm{a} 2}$ with the parameters of the pipes. (a) diameter $d$ varies while $D=1.0 \mathrm{~m}$ and $\lambda=0.02$; (b) diameter $D$ varies while $d=0.5 \mathrm{~m}$ and $\lambda=0.02$; (c) friction coefficient $\lambda$ varies while $D=1.0 \mathrm{~m}$ and $d=0.5 \mathrm{~m}$.

\subsubsection{Compressed Air Energy Storage System at Depth $h=1000 \mathrm{~m}$ and $\dot{m}_{\mathrm{a}}=100 \mathrm{~kg} / \mathrm{s}$}

For comparison, a CAES system at the depth of $1000 \mathrm{~m}$ is analyzed. The same parameters listed in Table 1 are used. The results are given in Table 2. It can be seen that the pressure loss in the water pipe is approximately $0.11 \mathrm{MPa}$, while that in the air pipe is $1.19 \mathrm{MPa}$. The output power of the CAES system is approximately $19.52 \mathrm{MW}$, which is $1.5 \mathrm{MW}$ higher than that at the depth of $500 \mathrm{~m}$. That is to say, the mass flow rate has a critical effect on the output power.

For the $10,000 \mathrm{~m}^{3}$ space volume, the power generation duration of the CAES system at the depth of $1000 \mathrm{~m}$ can be calculated according to Equation (9), and is approximately $3.49 \mathrm{~h}$.

\subsubsection{Maximum Output Power of the Compressed Air Energy Storage System}

For water pipes, the maximum water flow rate is limited due to the water hammer effect. For a steel pipe with wall thickness of $5 \mathrm{~mm}$ and diameter of $1 \mathrm{~m}$, if the yield strength of the steel is $235 \mathrm{MPa}$, the restricted speed in water pipe is approximately $3 \mathrm{~m} / \mathrm{s}[37,38]$. For the roadway with a depth of $500 \mathrm{~m}$, the maximum output power of the CAES system is calculated, considering of the water hammer effect in the water pipe. The parameters in Table 1 are used, and the results are listed in Table 3. It can be seen that the capacity of the system can be increased to $26.0 \mathrm{MW}$. 
Table 3. Results for a CAES system with water hammer velocity.

\begin{tabular}{cc}
\hline Parameter & Value \\
\hline$\dot{m}_{\mathrm{a}}$ & $144.85 \mathrm{~kg} / \mathrm{s}$ \\
$v_{\mathrm{a} 1}$ & $12 \mathrm{~m} / \mathrm{s}$ \\
$v_{\mathrm{a} 2}$ & $13.03 \mathrm{~m} / \mathrm{s}$ \\
$p_{\mathrm{a} 1}$ & $4.85 \mathrm{MPa}$ \\
$p_{\mathrm{a} 2}$ & $4.46 \mathrm{MPa}$ \\
$P_{\mathrm{g}}$ & $26.0 \mathrm{MW}$ \\
\hline
\end{tabular}

From Equation (8), it can be seen that there are other factors that influence the capacity of the system, such as the temperature and pressure of air at the inlet of turbines and the efficiency of turbines. By optimizing the factors, the capacity of the system can be improved further.

\section{Discussion}

\subsection{Extension of the New Compressed Air Energy Storage System}

In the new CAES system, the air pressure is determined by the pressure head of the reservoir. Therefore, for shallow roadways, the air pressure may be too low. Then, as the scale of the stored energy depends on the mass of the compressed air in the bags, larger storage volume should be used for shallow roadways, which will increase the investment of the system. Alternatively, the air pressure can be increased over the water pressure. Taking the roadway with $500 \mathrm{~m}$ depth as an example, the water pressure is $5 \mathrm{MPa}$. In practice, the air pressure in the flexible bags can be over $5 \mathrm{MPa}$, for example $8 \mathrm{MPa}$. The discharge of the flexible bag from $8 \mathrm{MPa}$ to $5 \mathrm{MPa}$ is a nonisobaric and nonisothermal process. The pressure and temperature decrease during releasing air process. The initial gas mass in the flexible bag is as follows:

$$
m_{a 0}=\frac{p_{a 0}}{Z R T_{a 0}} V_{\text {storage }}
$$

where $m_{a 0}$ is the initial air mass in the flexible bag; $p_{a 0}$ is the initial air pressure, which is $8 \mathrm{MPa}$; $T_{a 0}$ is the initial air temperature, which is equal to the surrounding rock temperature and assumed to be $283.15 \mathrm{~K}$ here; $\mathrm{Z}$ is the air compression coefficient, which is $0.97 ; R$ is the gas constant and equals to $287 \mathrm{~J} /(\mathrm{kg} \cdot \mathrm{K}) . V_{\text {storage }}$ is the volume of the roadway, which is $10,000 \mathrm{~m}^{3}$.

During the air releasing process from air pressure of $8 \mathrm{MPa}$ to $5 \mathrm{MPa}$, the air pressure at time $t$ is:

$$
p_{\mathrm{a}}=p_{\mathrm{a} 0}\left(\frac{m_{\mathrm{a} 0}-\dot{m} t}{m_{\mathrm{a} 0}}\right)^{k}
$$

where $\dot{m}$ is the air mass flow rate and assumed to be $100 \mathrm{~kg} / \mathrm{s} ; p_{\mathrm{a}}$ is the air pressure at time $t$, and $k$ is the adiabatic index, which is 1.4 .

According to Equations (10) and (11), the exhaust time can be calculated. The air pressure takes approximately $0.8 \mathrm{~h}$ to decrease from $8 \mathrm{MPa}$ to $5 \mathrm{MPa}$. When the air pressure is lower than $5 \mathrm{MPa}$, the water flows into the roadway and keeps the air pressure constant. Then, the following air releasing process is isobaric and isothermal. Therefore, during the releasing air process, the variation of air pressure in the flexible bag is shown in Figure 6.

It should be noted that according to the initial in situ stress, there may be tensile stress in the surrounding rock if the air pressure is too high. Then, some mechanical analysis on the surrounding rock of the roadway should be carried out for safety evaluation, which is beyond the scope of the present study. 


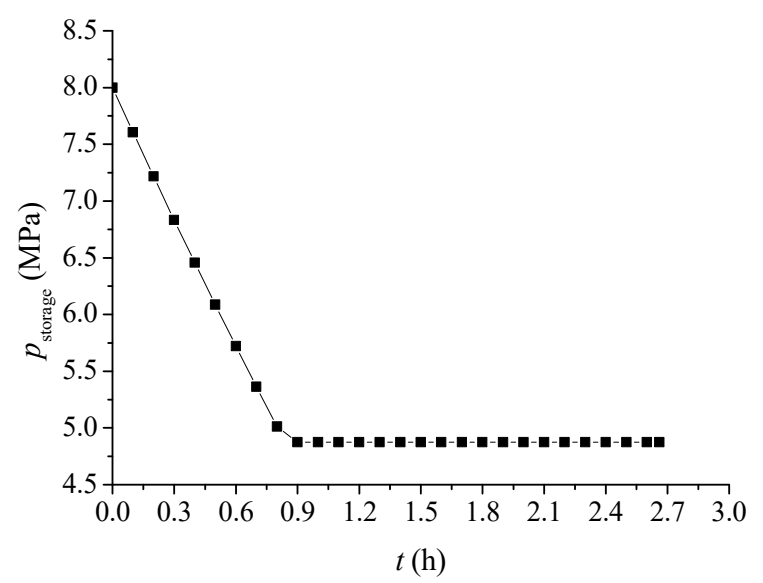

Figure 6. Variation of air pressure in the flexible bags with time during generation of electricity.

\subsection{Advantages of the New Compressed Air Energy Storage System}

From the analysis above, we can see that the roadways of underground coal mines can be used to implement large scale CAES systems. Meanwhile, according to the conditions of the coal mines, the pump-hydro and compressed air methods can be combined to realize a new CAES system with constant pressure. Compared with other CAES systems applied in salt caverns or steel tanks, the new system has the following advantages.

(1) Compared to the salt caverns, the roadways can be easily maintained. The surrounding rock can be reinforced by grouting, and lined with concrete, while the salt caverns are usually inaccessible. Meanwhile, when flexible bags are used, the air leakage can be well controlled in the roadways, while that in the salt caverns is a general risk.

(2) Compared to steel tanks, the investment is much lower and the capacity of the system can be much larger.

(3) Around the coal mines, there are generally power stations, and the generated power of the CAES system can be easily transferred to the power grid.

(4) As the air pressure and temperature are almost constant in the new CAES system, the design of the system is simpler, and the efficiency of the system will be higher.

(5) The underground coal mines generally have different mining levels, and the roadways have different depths. Therefore, the scale of the CAES system can be enlarged easily as required.

\section{Conclusions}

The present study focuses on the application of CAES systems in rock caverns. According to the special conditions of underground coal mines, a new CAES scenario was proposed. The new CAES system combines pumped-hydro and compressed-air methods, and features constant air pressure and temperature. The governing equations of the storing part of the system are derived. The main findings of the study are as follows:

(1) The compressed air is cooled to the temperature of the roadway. Therefore, there will be little thermal loss during storage of the air. Besides, the compressed air is stored in flexible bags, and the leakage of air is avoided.

(2) During release of the compressed air to generate electricity, the air pressure at the inlet of turbines is constant due to the pressure compensation of the pumped water. The value of the air pressure has a close relation to the diameters and friction coefficient of water and air pipes. The optimal diameters for water and air pipes in the present research are $1.0 \mathrm{~m}$ and $0.5 \mathrm{~m}$, respectively.

(3) Compared to other CAES systems, the proposed system has several advantages, and may provide a reference for the application of CAES in other rock caverns. 
Author Contributions: Conceptualization and methodology, K.Z. and H.Z.; writing—original draft preparation, K.D.; visualization, X.X.; funding acquisition, K.Z.

Funding: This study was funded by the Fundamental Research Funds for the Central Universities (Grant Number 2018ZZCX04).

Acknowledgments: We appreciate the detailed comments from the reviewers and editor, which have helped us to improve the paper greatly.

Conflicts of Interest: The authors declare that they have no conflict of interest.

\section{Abbreviations}

$\dot{m}_{a}$

$v_{\mathrm{a} 1}$

$\rho_{\mathrm{a} 1}$

$v_{\mathrm{a} 2}$

$\rho_{\mathrm{a} 2}$

$p_{\mathrm{a} 1}$

$p_{\mathrm{a} 2}$

Z

R

T

$d$

$b$

$g$

c

$\lambda$

h

mass flow of compressed air when deflating, $\mathrm{kg} / \mathrm{s}$

the velocity of the compressed air at the inlet of the air pipe, $\mathrm{m} / \mathrm{s}$

the density of the compressed air at the inlet of the air pipe, $\mathrm{kg} / \mathrm{m}^{3}$

the velocity of the compressed air at the outlet of the air pipe, $\mathrm{m} / \mathrm{s}$

the density of the compressed air at the outlet of the air pipe, $\mathrm{kg} / \mathrm{m}^{3}$

the pressure of compressed air at the inlet of air pipe, $\mathrm{MPa}$

the pressure of compressed air at the outlet of air pipe, $\mathrm{MPa}$

the compressibility factor

the gas constant, $287 \mathrm{~J} /(\mathrm{kg} \cdot \mathrm{K})$

the air temperature in kelvin, $\mathrm{K}$

the diameter of the air pipe, $\mathrm{m}$

a parameter and equals to $\frac{2 g}{Z R T}$

the coefficient of gravity, $9.8 \mathrm{~m} / \mathrm{s}^{2}$

a parameter and equal to $\lambda \frac{16 Z R T}{\pi^{2} d^{5}}$

the friction coefficient along the pipe

height from the roadway to the reservoir or pressure head, $\mathrm{m}$

the water pressure at the bottom of the water pipe, $\mathrm{MPa}$

the density of water, $\mathrm{kg} / \mathrm{m}^{3}$

the water velocity in the water pipe, $\mathrm{m} / \mathrm{s}$

the major head loss along the water pipe, $\mathrm{m}$

the minor head loss at the junction of water pipe and roadway, $\mathrm{m}$

the local friction coefficient

the diameter of the water pipe, $m$

the output power of electric generator, MW

the air temperature at the inlet of the turbines, $\mathrm{K}$

the atmospheric pressure, $\mathrm{MPa}$

the efficiency of turbines

the efficiency of electric generator

power generation duration, $\mathrm{s}$

the air density in the flexible bag, $\mathrm{kg} / \mathrm{m}^{3}$

the volume of the roadway, $\mathrm{m}^{3}$

the air pressure in the flexible bag, $\mathrm{MPa}$

the initial air mass in the flexible bag, $\mathrm{kg}$

the initial air pressure in the flexible bag, $\mathrm{MPa}$

the initial air temperature in the flexible bag, $\mathrm{K}$

the air pressure in the flexible bag at the time $t, \mathrm{MPa}$

the adiabatic index

\section{References}

1. Che, Q.; Lou, S.; Wu, Y.; Zhang, X.; Wang, X. Optimal Scheduling of a Multi-Energy Power System with Multiple Flexible Resources and Large-Scale Wind Power. Energies 2019, 12, 3566. [CrossRef]

2. Dong, F.; Ding, X.; Shi, L. Wind Power Pricing Game Strategy under the China's Market Trading Mechanism. Energies 2019, 12, 3456. [CrossRef] 
3. Akinyele, D.O.; Rayudu, R.K. Review of energy storage technologies for sustainable power networks. Sustain. Energy Technol. Assess. 2014, 8, 74-91. [CrossRef]

4. Chen, H.; Cong, T.N.; Yang, W. Progress in electrical energy storage system: A critical review. Prog. Nat. Sci. 2009, 19, 291-312. [CrossRef]

5. Nag, S.; Lee, K.Y.; Suchitra, D. A Comparison of the Dynamic Performance of Conventional and Ternary Pumped Storage Hydro. Energies 2019, 12, 3513. [CrossRef]

6. Mahlia, T.; Saktisahdan, T.; Jannifar, A.; Hasan, M.H.; Matseelar, H. A review of available methods and development on energy storage; technology update. Renew. Sustain. Energy Rev. 2014, 33, 532-545. [CrossRef]

7. Liu, J.; Xia, H.; Chen, H.; Tan, C.; Xu, Y. A novel energy storage technology based on liquid air and its application in wind power. J. Eng. Thermophys. 2010, 31, 1993-1996.

8. Pimm, A.J.; Garvey, S.D.; de Jong, M. Design and testing of energy bags for underwater compressed air energy storage. Energy 2014, 66, 496-508. [CrossRef]

9. Castellani, B.; Presciutti, A.; Morini, E.; Filipponi, M.; Nicolini, A.; Rossi, F. Use of phase change materials during compressed air expansion for isothermal CAES plants. J. Phys. Conf. Ser. 2017, 923, 012037. [CrossRef]

10. Guo, H.; Xu, Y.; Chen, H.; Guo, C.; Qin, W. Thermodynamic analytical solution and exergy analysis for supercritical compressed air energy storage system. Appl. Energy 2017, 199, 96-106. [CrossRef]

11. Li, X.M.; Yang, K.; Zhang, Y. Thermodynamic analysis of storage cavern in advanced adiabatic compressed air energy storage system. J. Eng. Thermophys. 2015, 36, 513-516.

12. Crotogino, F.; Mohmeyer, K.-U.; Scharf, R. Huntorf CAES: More than 20 years of successful operation. In Proceedings of the Spring 2001 Meeting, Orlando, FL, USA, 15-18 April 2001.

13. Crotogino, F. Compressed air storage. In Energy Autonomy: Storing Renewable Energies; Earthscan Publicoctions Ltd.: Hannover, Germany, 2006; pp. 37-39.

14. Yang, C.; Wang, T.; Ma, H.; Li, Y.; Shi, X.; Daemen, J.J.K. Feasibility analysis of using horizontal caverns for underground gas storage: A case study of Yunying salt district. J. Nat. Gas Sci. Eng. 2016, 36, 252-266. [CrossRef]

15. Luo, P.; Chen, N. Abandoned coal mine tunnels: Future heating/power supply centers. Min. Sci. Technol. 2011, 21, 637-640. [CrossRef]

16. Fosnacht, D.R. Pumped Hydro Energy Storage (PHES) Using Abandoned Mine Pits on the Mesabi Iron Range of Minnesota-Final Report; University of Minnesota Duluth: Duluth, MN, USA, 2015.

17. Zhou, Y.; Xia, C.; Zhao, H. A method for estimating air leakage through inner seals and mechanical responses of the surrounding rock of lined rock caverns for compressed air energy storage. Chin. J. Rock Mech. Eng. 2017, 36, 297-309. (In Chinese)

18. Ye, B.; Cheng, Z.; Peng, Y. Analysis of Influence Factors on Air Tightness of Underground Cavern for Compressed Air Energy Storage. J. Tongji Univ. 2016, 4, 1526-1532. (In Chinese)

19. Zimmels, Y.; Kirzhner, F.; Krasovitski, B. Design criteria for compressed air storage in hard rock. Energy Environ. 2002, 13, 851-872. [CrossRef]

20. Rutqvist, J.; Kim, H.M.; Ryu, D.W.; Synn, J.H.; Song, W.K. Modeling of coupled thermodynamic and geomechanical performance of underground compressed air energy storage in lined rock caverns. Int. J. Rock Mech. Min. Sci. 2012, 52, 71-81. [CrossRef]

21. Zhang, G.; Li, Y.; Daemen, J.J.K. Geotechnical feasibility analysis of compressed air energy storage (CAES) in bedded salt formations: A case study in Huai'an city, China. Rock Mech. Rock Eng. 2015, 48, 2111-2127. [CrossRef]

22. Kim, H.M.; Rutqvist, J.; Kim, H.; Park, D.; Ryu, D.W.; Park, E.S. Failure monitoring and leakage detection for underground storage of compressed air energy in lined rock caverns. Rock Mech. Rock Eng. 2016, 49, 573-584. [CrossRef]

23. Terashita, F.; Takagi, S.; Kohjiya, S. Airtight butyl rubber under high pressures in the storage tank of CAES-G/T system power plant. J. Appl. Polym. Sci. 2005, 95, 5. [CrossRef]

24. George, S.C.; Thomas, S. Transport phenomena through polymeric systems. Prog. Polym. Sci. 2001, 26, 985-1017. [CrossRef]

25. Galvin, J.M. Ground Engineering-Principles and Practices for Underground Coal Mining; Springer: Berlin/Heidelberg, Germany, 2016.

26. Kulatilake, P.H.S.W.; Wu, Q.; Yu, Z.; Jiang, F. Investigation of stability of a tunnel in a deep coal mine in china. Int. J. Min. Sci. Technol. 2013, 23, 579-589. [CrossRef] 
27. Lund, H.; Salgi, G. The role of compressed air energy storage (CAES) in future sustainable energy systems. Energy Convers. Manag. 2009, 50, 1172-1179. [CrossRef]

28. Venkataramani, G.; Parankusam, P.; Ramalingam, V.; Wang, J. A review on compressed air energy storage-A pathway for smart grid and polygeneration. Renew. Sustain. Energy Rev. 2016, 62, 895-907. [CrossRef]

29. Budt, M.; Wolf, D.; Span, R.; Yan, J. A review on compressed air energy storage: Basic principles, past milestones and recent developments. Appl. Energy 2016, 170, 250-268. [CrossRef]

30. Proczka, J.J.; Muralidharan, K.; Villela, D.; Simmons, J.H.; Frantziskonis, G. Guidelines for the pressure and efficient sizing of pressure vessels for compressed air energy storage. Energy Convers. Manag. 2013, 65, 597-605. [CrossRef]

31. Wang, J.; Lu, K.; Ma, L.; Wang, J.; Dooner, M.; Miao, S.; Li, J.; Wang, D. Overview of compressed air energy storage and technology development. Energies 2017, 10, 991. [CrossRef]

32. Castellani, B.; Presciutti, A.; Filipponi, M.; Nicolini, A.; Rossi, F. Experimental Investigation on the Effect of Phase Change Materials on Compressed Air Expansion in CAES Plants. Sustainability 2015, 7, 9773-9786. [CrossRef]

33. Lyons, W.C. Standard Handbook of Petroleum E Natural Gas Engineering; Gulf Professional Publishing: Houston, TX, USA, 1996; Volume 2.

34. Rojey, A.; Jaffret, C. Natural Gas Processing Transport; Editions Technip: Paris, France, 1997.

35. Rochelle, A. Natural gas-powered generator provides alternate source of power. Cent. Penn Bus. J. 1998, 4, $17-26$.

36. Baqari, F.; Vahidi, B. Small-compressed air energy storage system integrated with induction generator for metropolises: A case study. Renew. Sustain. Energy Rev. 2013, 21, 365-370. [CrossRef]

37. Ghidaoui, M.S.; Zhao, M.; McInnis, D.A.; Axworthy, D.H. A review of water hammer theory and practice. Appl. Mech. Rev. 2005, 58, 49-76. [CrossRef]

38. Jia, Y.; Wang, Z.; Zheng, X.; Li, Y. A study on limit velocity and its mechanism and implications for alluvial rivers. Int. J. Sediment Res. 2016, 31, 205-211. [CrossRef]

(C) 2019 by the authors. Licensee MDPI, Basel, Switzerland. This article is an open access article distributed under the terms and conditions of the Creative Commons Attribution (CC BY) license (http://creativecommons.org/licenses/by/4.0/). 